\title{
Unidades de seleção tecnológica e inovação na construção habitacional no Brasil
}

\author{
Units of technological selection and innovation in housing \\ construction in Brazil
}

\section{Maria Luiza de Castro \\ Paulo Gustavo von Kruger}

\section{Resumo}

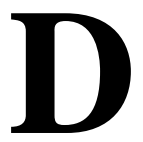

entro de uma perspectiva que considera a evolução do sistema tecnológico como resultado de uma seleção do tipo darwinista, aspectos históricos, culturais e sociais, entre outros, são elementos indissociáveis do processo dinâmico de crescimento e mudança, o que demanda uma abordagem que analise a competitividade setorial além dos limites estritamente econômicos. Esse enfoque abrangente conduz a um aprendizado sobre a evolução tecnológica, o que é extremamente relevante para a análise de desempenho das tecnologias e também para a procura de soluções mais adequadas para cada contexto. Este artigo tem como objetivo destacar elementos importantes para a compreensão da evolução do sistema tecnológico na construção habitacional no Brasil nos últimos anos, procurando trazer subsídios não só para uma avaliação dos efeitos das interações entre novas tecnologias, a Economia e o meio, como também para a prospecção de um espaço coerente e de um mundo sustentável.

Palavras-chave: Competitividade setorial. Seleção tecnológica. Construção. Habitação. Inovação. Políticas públicas.

\footnotetext{
Abstract

Within a perspective that considers the evolution of the technological system as a result of a Darwinian-like selection, certain elements, such as historical, cultural and social ones, must be included in the analysis of the dynamics of growth and change, which demands an approach that transcends the limits of Economics. This

comprehensive approach leads to a learning process about technology that is extremely relevant to the analysis of the performance of new systems and also to the search of the best-suited solutions for each context. The aim of this paper is to highlight elements that are important for understanding the evolution of the technological system in housing construction in Brazil in recent years. It seeks not only to get a better assessment of the effects of the interactions between new technologies, Economics and the environment, but also to prospect coherent living spaces and a sustainable world.

Keywords: Sector competitiveness. Technology selection. Construction. Housing. Innovation. Public policies.
}

Maria Luiza de Castro Universidade Federal de Minas Gerais Belo Horizonte - MG - Brasil

Paulo Gustavo von Kruger Universidade Federal de Minas Gerais Belo Horizonte - MG - Brasil

Recebido em 19/04/13 Aceito em 17/07/13 


\section{Introdução}

Um início de industrialização observada no setor de construção de habitação coletiva no Brasil revela que determinados sistemas tecnológicos, já disponíveis em certos casos há décadas, começam, enfim, a ser difundidos. Esse processo tem sido atribuído principalmente a um fator econômico: o encarecimento da mão de obra não especializada, que diminui as vantagens da utilização de sistemas construtivos tradicionais e viabiliza financeiramente a introdução de sistemas industrializados. Entretanto, a evolução tecnológica diz respeito às transformações das condições da existência, e seu estudo carece de sentido se não inserir a análise da história, da cultura, da estrutura social e outros. Dentro de uma perspectiva que considera a evolução do sistema tecnológico como resultado de um processo de seleção do tipo darwinista, todos esses aspectos são elementos indissociáveis do processo dinâmico de crescimento e mudança, o que demanda uma análise que transcenda limites estritamente econômicos (ALLEN, 1988).

De acordo com essa visão evolucionária, existem sempre diversas espécies tecnológicas em competição, e aquelas que acabam por ser adotadas correspondem às mais adaptadas ao meio, no qual ocorrem várias interações e trocas. As inovações constituem a resposta mais adequada para mudanças tangíveis ou intangíveis ocorridas nesse meio em determinado momento. Dessa forma, é possível estabelecer uma analogia biológica que coloca a adoção de uma tecnologia como resultado de um processo de seleção natural (ALLEN, 1988).

A seleção pode ocorrer em diversos níveis: no que diz respeito à construção habitacional, a espécie tecnológica predominante pode ser a mais adequada não só em termos econômicos, ou de sofisticação tecnológica, mas também em termos de adequação à realidade social, às orientações políticas ou aos padrões de comportamento - e estas diversas "unidades de seleção" é que determinam as novas espécies que se tornam bem sucedidas (DOSI; NELSON, 1994).

Esse enfoque tem suas origens na proposta pioneira de Schumpeter (1985) para a compreensão dos sistemas microeconômicos, ampliada pelos teóricos evolucionários, como Dosi, Freeman, Nelson e Winter, e oferece uma perspectiva de aplicação interdisciplinar privilegiada, uma vez que atribui destaque especial à questão da inovação e possibilita sua inserção dentro de um contexto de análise sistêmico.
Este artigo procura investigar os diversos elementos do contexto - tanto do ponto de vista econômico como institucional (político, cultural, social, etc.), com o objetivo de entender o surgimento das novas espécies tecnológicas - e também avaliar seus efeitos no meio, sua adequação a ele e seu desempenho.

\section{Inovação como processo de seleção natural}

O papel da demanda e da oferta na inovação é em geral discutido a partir de duas teorias: a primeira delas é a teoria da demand pull (indução pela demanda) e, segundo ela, os avanços tecnológicos seriam resultado de novas demandas do mercado. Apesar de esta investigação trazer subsídios para a análise, ela não explica, por si só, determinadas questões, tais como a capacidade de invenção, a razão pela qual certos desenvolvimentos tecnológicos acontecem em detrimento de outros ou o momento em que eles ocorrem; além disso, ela atribui à tecnologia um papel extremamente passivo, subestimando a complexidade e o papel da incerteza no processo inovador (DOSI, 2006).

A outra teoria é conhecida como tecnology push (impulso pela técnica): de acordo com ela, o desenvolvimento tecnológico seria relativamente autônomo e também responsável pelo surgimento de novos produtos. Essa visão desconsidera, entretanto, as relações da pesquisa e evolução científica com a economia (DOSI, 2006).

Como tentativa de superar essas limitações, as teorias evolucionárias, a partir dos anos 1980, têm resgatado a questão da inovação, com base em uma visão schumpeteriana, dentro da qual demanda e oferta são apenas alguns dos fatores que contribuem para definir o contexto em que as tecnologias desenvolvem-se. Para Schumpeter (1985), a evolução ocorre com consequência de determinadas mudanças, entre as quais está a introdução de um novo bem no mercado, ou o acréscimo de uma nova qualidade a ele; a introdução de novos métodos de produção; a abertura de novos mercados; a introdução de novas fontes de matérias-primas; ou novas formas de organização industrial.

A inovação resulta, assim, do emprego de novos recursos e de novas formas de produzir, o que gera descontinuidades e quebra rotinas no sistema econômico. Schumpeter (1985) descreve um processo de destruição criadora, no qual a adoção do novo implica a superação e a destruição do antigo, dentro de um ambiente de competição. Para 
ele, é o empresário empreendedor quem coloca em prática as inovações, e o ambiente influencia decisivamente os agentes na seleção das condutas a serem adotadas em cada momento (KUPFER, 1996). O processo completa-se com a multiplicação da inovação, uma vez que, tão logo lançada, ela atrai os imitadores, permitindo sua propagação.

As teorias evolucionárias incorporam a visão de dinâmica de Schumpeter e ampliam ainda mais a perspectiva, enfatizando a "[...] heterogeneidade na solução ideal [...]" $\quad-$ considerando comportamentos ditados por regras diversas, abrindo espaço permanente para a procura de novas soluções (DOSI; NELSON, 1994, p. 157).

Nesse sentido, o paradigma vigente e as trajetórias tecnológicas - identificáveis devido à existência de certas regularidades significativas na evolução das tecnologias ao longo do tempo (DOSI, 2006) configuram a estrutura do meio; eles ordenam o progresso técnico e definem os limites da busca e seleção de inovações, até que surja um novo paradigma: a mudança de paradigma é, então, uma transformação radical no senso comum técnico e de gestão, na busca de uma maior produtividade e lucratividade (FREEMAN; PEREZ, 1988), uma mudança na estrutura do meio.

Segundo Dosi (2006), o ambiente, ou meio, afeta o progresso técnico de dois modos:

(a) inicialmente ele seleciona a direção das mutações (definindo o paradigma tecnológico); e

(b) em seguida, ele seleciona entre os mutantes as espécies mais bem adaptadas.

O ambiente competitivo é baseado na existência de assimetrias técnico-econômicas (diferentes capacidades); na existência de variedade tecnológica (várias tecnologias em competição); e na existência de diversidade comportamental entre os agentes (KUPFER, 1996). Essas assimetrias permitem um melhor acoplamento entre determinadas espécies - as mais adaptadas - e o meio.

O sistema tecnológico inclui, então, todas as espécies tecnológicas em competição, que sofrem estímulos do meio e mostram-se mais ou menos adaptadas às contingências, segundo diversas "unidades de seleção". Essas "unidades de seleção" podem ser, por exemplo, a política operante ou um padrão de comportamento vigente (DOSI; NELSON, 1994). Os mecanismos que definem a maior adaptação envolvem a interação com o meio, através da qual cada espécie sofre diversas pressões, tais como demandas de exequibilidade, eficiência, lucratividade, negociabilidade ou oportunidades de crescimento
(DOSI; NELSON, 1994; DOSI, 2006). A adequação pode ocorrer no nível das sociedades, no das próprias empresas ou no dos mercados.

O processo de inovação não é, portanto, a simples introdução de algo novo, nem "um fenômeno estanque, aleatório" ou um ato único; ao contrário, trata-se de "uma série de atos unidos no processo inventivo" (CÁRIO; PEREIRA, 2001), de um processo social que dá suporte econômico à novidade técnica e segue procedimentos estabelecidos, em que estão presentes mecanismos de busca, rotinas e seleção. Esse processo desenvolve formas de aprendizado; envolve organização formal que depende de infraestrutura tecnológica e gastos para pesquisa; e seus avanços decorrem também de relações entre a ciência e a tecnologia (KUPFER, 1996).

A compreensão do processo de seleção tecnológica é extremamente relevante para a análise de desempenho das tecnologias e também para a procura de soluções mais coerentes para mudanças desejadas. Muitas vezes, a seleção natural privilegia questões econômicas ou conjunturais, em detrimento de demandas sociais ou mesmo técnicas. A análise dos mecanismos dessa seleção abre espaço para tentativas de redirecionamento do processo evolutivo, por meio da promoção de "perturbações" ao sistema, e tem o potencial de contribuir para a busca de inovações que levem de uma forma mais abrangente à prospecção de um mundo sustentável.

Entretanto, é importante ter a consciência de que a ordem na evolução é o produto não intencional da dinâmica do sistema (DOSI; ORSENIGO, 1988), e a complexidade das interações faz com que os mecanismos na seleção ex ante das direções tecnológicas sejam extremamente incertos (DOSI, 2006).

\section{Influências na construção da habitação: a conjuntura econômica e social}

O panorama econômico, ao qual em geral é atribuído todo o desencadeamento das mudanças, tem, efetivamente, importância indiscutível para a adoção e difusão das inovações. As grandes mudanças na conjuntura econômica no Brasil na última década têm criado um meio que pode ser propício à difusão de novas espécies tecnológicas no que diz respeito à construção habitacional.

Segundo Freeman e Perez (1988), um dos fatoreschave que incita a adoção de mudanças é a percepção no mercado de que o custo de um sistema construtivo está baixo ou diminuindo de 
maneira significativa. Pequenas mudanças têm pouco ou nenhum efeito no comportamento de engenheiros, planejadores e pesquisadores. Somente mudanças maiores e persistentes têm o poder de transformar as regras até então adotadas.

O senso comum tem apontado o elevado custo da mão de obra como responsável pela adoção gradual de tecnologias industrializadas na construção. O custo da mão de obra é, entretanto, apenas um dos diversos fatores que influenciam a seleção tecnológica no setor: seu aumento, no caso de métodos construtivos tradicionais, faz com que, comparativamente, o custo das soluções industrializadas esteja diminuindo. Esse fato, associado à agilidade produtiva e aos retornos mais rápidos dos investimentos nos novos processos, tem levado algumas empresas a adotá-las. Trata-se de um procedimento de busca de maximização (DOSI, 2006), e, do ponto de vista econômico, questões como a escolha entre duas técnicas de construção bem definidas para dado custo sempre envolverão o cálculo visando a uma maximização de receitas - embora este não seja um critério de análise suficiente.

O aumento no nível salarial dos trabalhadores não é um "fenômeno estanque" e ele se insere dentro de um processo de evolução no sistema socioeconômico do país. Entre abril de 2004 e abril de 2008, a classe C cresceu 22,8\%, alcançando $51,89 \%$ da população brasileira. Nesse mesmo período, as classes B e A cresceram 33,6\%. Entre 2004 e 2006 (e a partir de 2001 para os segmentos mais pobres da população), esse fato é atribuído, em parte, às “[...] altas transferências previdenciárias, contributivas ou não, associadas aos reajustes do salário mínimo [...]” e, em parte, ao aumento de renda do trabalho. Mas a partir de 2006, a ênfase tem estado no "[...] protagonismo da renda do trabalho em geral e da geração de empregos formais, em particular [...]" (NERI, 2008, p. 44).

Em pesquisa sobre o perfil dos trabalhadores da construção civil entre 2004 e 2009, Kirchner et al. (2011) identificaram um aumento de 98,58\% na quantidade de trabalhadores no setor, aumento que não atende, porém, ao expressivo crescimento dele, seja em termos quantitativos (OSCAR, 2012), seja em termos qualitativos: a produtividade da mão de obra da construção civil no Brasil no setor residencial ainda é de $35 \%$ em relação à dos Estados Unidos. No setor de construção para classe média, ela é de $50 \%$, e no setor de construção de baixa renda, de $20 \%$ (NERI, 2011).

$\mathrm{O}$ enriquecimento da população e o desenvolvimento social possibilitam a evolução de setores voltados para seu suprimento, e, no Brasil, tem-se observado um grande aumento na demanda por habitação. A existência de maior quantidade de consumidores leva à necessidade de maior rapidez e eficiência no fornecimento de moradia, criando condições favoráveis para a adoção de inovações construtivas.

Esse mesmo enriquecimento pode, por outro lado, gerar circunstâncias que contribuam para a perpetuação do uso das tecnologias tradicionais. O aporte das novas tecnologias em termos de eficiência é refletido em aumento de lucratividade ou oportunidades de crescimento para as empresas. Porém, quando os ganhos são facilmente atingidos mesmo sem inovação tecnológica, a tendência é a de que se estabeleça uma dinâmica linear.

Assim, a escassez da oferta pode levar a um menor nível de exigência na demanda: o déficit habitacional observado no Brasil era estimado em 5,546 milhões de domicílios em 2008, dos quais 4,629 milhões, ou 83,5\%, localizados nas áreas urbanas (BRASIL, 2011). Em relação ao estoque de domicílios particulares permanentes do país, o déficit correspondia a 9,6\%, sendo 9,4\% nas áreas urbanas e $11 \%$ nas rurais. Neri (2011) fala de uma demanda reprimida por moradia de 13 milhões de unidades, que deverá ser suprida no longo prazo. Esse déficit faz com que a oferta de imóveis, mesmo quando inadequada, seja prontamente absorvida, perpetuando uma situação na qual o empreendedor não se preocupa em inovar.

Condições tais como o aumento da oferta de crédito imobiliário, a diminuição de juros, o alongamento de prazos para pagamento, a melhoria da atratividade do setor enquanto investimento e outras questões dessa ordem - que têm sido observadas no Brasil nos últimos anos aumentam a demanda e contribuem para que não haja pressões de mudança tecnológica.

Assim, embora o meio socioeconômico estimule ou "perturbe" (LUHMANN; TORRES NAFARRATE, 2009) o sistema tecnológico, e dentro de sua estrutura existam possibilidades de reorganização que incluem a inovação, é difícil determinar a priori quais dessas perturbações vão efetivamente levar o sistema a reorganizar-se internamente. Apesar dessa incerteza, é certo, porém, que as políticas públicas são de extrema relevância enquanto provocadoras de perturbações e estímulos. 


\section{Influência das politicas públicas na inovação tencológica}

A indústria da construção tem sua dinâmica e trajetórias próprias e reage de uma maneira particular. Ela é, em geral, extremamente dependente de programas governamentais tais como os de provimento de habitação de baixa renda ou obras de infraestrutura. Essa dependência foi sentida no país com o encaminhamento neoliberal da política econômica a partir de meados da década de 1980, que levou o setor a um período de crise (SILVA; AMORIM, 2001): o direcionamento econômico gerou, naquela ocasião, uma queda de financiamentos de origem estatal, tendo provocado um "[...] retraimento em relação às inovações tecnológicas [...]" devido à incerteza no fluxo financeiro (ZIGMANTAS, 2005, p. 61). Com a extinção do BNH, em 1986, suprimiu-se qualquer política pública habitacional e urbana consistente, e a construção informal (as favelas) apresentou um crescimento expressivo (MARICATO, 2005). A crise do setor acompanhou a recessão do país, que culminou com um declínio de 2,3\% da atividade econômica, em 2003. Em contrapartida, houve uma tentativa de reação no setor da construção, que procurou superar a crise por meio da introdução de inovações: a redução nas margens de lucro exigiu maior produtividade das empresas, dando origem a um processo de tentativa de reestruturação e inovação tecnológica (AMORIM, 1996).

Entre as iniciativas voltadas para a introdução de mudanças nessa época, destacam-se esforços institucionais tais como o programa de Vilas Tecnológicas - pequenos conjuntos habitacionais que constituíam espaços de experimentação para testar sistemas construtivos industrializados, em Ribeirão Preto, Bauru, Curitiba, Brasília Goiânia e outras cidades - que foram, todavia, construídos sem o controle de questões ligadas ao desempenho (ZIGMANTAS, 2005); ou a criação do Programa Brasileiro da Qualidade e Produtividade na Construção Habitacional (PBQP-CH), no final de 1997 (CARDOSO, 1998), que teve seu escopo ampliado para Programa Brasileiro da Qualidade e Produtividade do Habitat (PBQP-H), em 2000. Foi também nessa época que se fortaleceu, no país, a consciência da necessidade da avaliação de desempenho: o extinto BNH contratara em 1981 o IPT para sistematizar o conhecimento sobre a Avaliação de Desempenho de Sistemas Construtivos Inovadores, gerando diretrizes que passaram a ser adotadas também pela Caixa Econômica Federal (CEF). No final de 1999, a CEF contratou, através da Finep, o Cobracon-
ABNT para a elaboração da Norma Brasileira para Avaliação de Desempenho (ZIGMANTAS, 2005) - documento cuja redação inicial foi apresentada em 2001 e vem desde então sendo discutido no meio técnico, com publicações provisórias, devendo entrar em vigor em 2013.

Entretanto, todo esse movimento em busca da inovação não levou à difusão das tecnologias industriais ou inovadoras: na adversidade, a tendência é que as grandes empresas procurem aprimorar aspectos da tecnologia que dominam, ao invés de adotar novas tecnologias, para não tornar os recursos e conhecimentos dos quais dispõem obsoletos (FREEMAN; PEREZ, 1988). Além disso, a seleção tecnológica na construção civil é muitas vezes politicamente manipulada para que haja uma absorção da mão de obra sem especialização. O resultado foi a continuidade da prevalência de uma trajetória baseada em tecnologias convencionais e tradicionais

A partir de 2004, a situação econômica começou a reverter-se, e no ano seguinte os níveis de crescimento da construção ultrapassaram o da atividade econômica como um todo no país. Isso ocorreu devido a uma grande mudança no direcionamento das políticas públicas de habitação, ocasionada, sobretudo, pela criação do Ministério das Cidades, em 2003, e pela instalação do Conselho Nacional das Cidades, que começou a funcionar em 2004. Uma nova política nacional de habitação foi desenvolvida com dois focos: a ampliação do mercado privado (restrito até então ao segmento de luxo), para que este atendesse também às classes médias emergentes; e ações de promoção pública, para resolver o problema da população de rendas mais baixas, especialmente aquelas situadas no intervalo de 0 a 5 salários mínimos (MARICATO, 2005).

Para o desenvolvimento do mercado privado, a Lei n. 10.931 foi aprovada em 2004 (BRASIL, 2004), com o objetivo de dar segurança jurídica e econômica às empresas com relação à inadimplência. Além disso, foi aprovada pelo Conselho Monetário Nacional a Resolução n. 3.259, que tornou desvantajosa para os bancos a retenção de recursos da poupança privada, no Banco Central, obrigando o investimento de parte deles em atividade produtiva (MARICATO, 2005).

Para a faixa da chamada habitação de interesse social, houve uma ampliação de recursos e subsídios: em 2005, foi aprovada a Lei n. 11.124 (BRASIL, 2005), que instituiu o Sistema Nacional de Habitação de Interesse Social (SNHIS), o Fundo Nacional de Habitação de Interesse Social (FNHIS) e seu respectivo Conselho Gestor; com a implementação desse fundo, estados e municípios 
foram incorporados ao sistema para ampliar o esforço de dar uma resposta massiva ao problema da habitação (MARICATO, 2006). Em 2007, o orçamento do FGTS para habitação atingiu R \$ 7 bilhões, e o subsídio total atingiu R $\$ 3,1$ bilhões, provenientes da Resolução n. 460/2005 do FGTS e do aumento dos recursos fiscais (MOYSÉS; BORGES, 2011). A ampliação de recursos também se deu por meio de outras fontes, tais como o Fundo de Arrendamento Residencial (FAR), o Fundo de Desenvolvimento Social (FDS), o Fundo de Amparo ao Trabalhador (FAT), o Orçamento Geral da União (OGU), a Caixa Econômica Federal (CEF) e o Sistema Brasileiro de Poupança e Empréstimo (SBPE) (MARICATO, 2005; MOYSÉS; BORGES, 2011).

A iniciativa privada foi ainda estimulada pela injeção de grandes somas de recursos governamentais nos novos programas, como o PAC Habitação e o Minha Casa Minha Vida (MCMV), lançado em abril de 2009 e revisado em 2011, levando, assim, à consolidação de um mercado popular de habitação. A abertura de capitais de empresas imobiliárias na Bolsa, a partir de 2006, por sua vez, permitiu a captação de mais de 20 bilhões de dólares no mercado de capitais (MOYSÉS; BORGES, 2011). Outros incentivos, tais como a criação de Regime Especial de Tributação da Construção Civil (RET), em 2004, que substitui o PIS, a Cofins, o Imposto de Renda da Pessoa Jurídica e a Contribuição Social sobre o Lucro Líquido (CSLL), bem como a gradativa ampliação desse benefício por meio da diminuição da alíquota para a faixa da habitação de interesse social (LIMA; OLIVEIRA, 2011), completam um contexto que possibilitou um expressivo crescimento no faturamento das grandes construtoras do país (correspondente a $111 \%$ entre 2004 e 2010 para as 10 maiores delas) (GODEIRO; MONTEIRO; MARQUES, 2010).

Tal arcabouço institucional foi elaborado na expectativa de que a partir da reação do mercado houvesse uma ampliação do acesso à moradia para a população situada entre cinco e dez salários mínimos e que as operações estruturadas (parceria público/público) fossem "[...] eficazes ao priorizar as faixas situadas abaixo de cinco salários mínimos [...]" (MARICATO, 2006, p. 218).

Conforme balanço da CEF, o volume de crédito imobiliário alcançou o recorde de 47 bilhões no ano de 2009, contra cerca de 5 bilhões em 2002, sendo o MCMV responsável por um terço das novas unidades habitacionais financiadas e quase $50 \%$ das contratações de 2010 (MOYSÉS; BORGES, 2011).
As políticas públicas do setor habitacional permitiram, então, uma verdadeira revolução no panorama da construção nacional. A articulação política para o desenvolvimento da construção para a baixa renda mostrou-se, portanto, bastante bemsucedida, e a evolução do sistema habitacional do país contemplou diversos dos objetivos projetados, mas elas geraram também outros efeitos não previstos ou não desejados.

Um dos principais efeitos negativos foi o aumento vertiginoso do custo da construção, elevando em consequência os preços dos imóveis. Lima Júnior (2011) atribui essa elevação a cinco fatores estruturais:

(a) ao aumento no preço dos terrenos;

(b) ao aumento dos custos de obtenção do direito de construir (por exemplo, devidos aos custos de outorga onerosa, cada vez mais presente no mercado);

(c) ao crescimento dos custos acima do INCC/FGV (devido à margem especulativa de subempreiteiras, ante a pressão da demanda);

(d) ao crescimento de custos de construção devido à natureza dos processos utilizados no mercado; $\mathrm{e}$

(e) à imposição de margens de segurança como precaução para contingências.

Em face desse panorama, o grande desafio que se coloca para as empresas é, portanto, adequar não só sua estrutura gerencial e produtiva, mas também sua visão estratégica, para atender às novas demandas e produzir imóveis de custo reduzido com qualidade. Apesar de alguns avanços, elas têm continuado, porém, a apresentar baixos níveis de qualidade da execução e de gerenciamento das obras.

A falta de adequação reflete-se nos atrasos para a conclusão das obras, e mesmo as grandes empresas não estão conseguindo cumprir os prazos de construção projetados: por ocasião de uma pesquisa realizada pela revista Exame (OSCAR, 2012) em fevereiro de 2012, cerca de 800.000 famílias aguardavam a entrega de imóveis comprados na planta, com atrasos de até 15 meses, revelando erros de estratégia de organização, mas também uma falta de domínio tecnológico. As empresas demonstram, assim, "[...] problemas naquilo que deveria ser sua especialidade: construir [...]", além de dificuldades financeiras, expressas por perdas da ordem de $39 \%$ no Ibovespa e endividamento de $68 \%$ em 2011 (OSCAR, 2012, p. 34). Entre as adversidades enfrentadas, a principal queixa dos construtores é o encarecimento e o despreparo da mão de obra. 
Dentro de um contexto completamente orquestrado para o favorecimento do acesso à moradia, ressente-se, então, de uma negligência com questões que possam garantir a qualidade de sua construção. A linha de financiamento prevista para incentivo à industrialização não tem sido suficiente para motivar os construtores. Por outro lado, a limitação das iniciativas de educação e treinamento de mão de obra constitui, evidentemente, um dos grandes problemas que emergem. Nesse sentido, uma redução na intensidade da mão de obra nos processos e sua qualificação contribuiriam para um melhor resultado das empresas.

Mas existem ainda questões acessórias, bem como certas regras instituídas que continuam a reforçar o tradicionalismo, exercendo pressão para a persistência de uma trajetória tecnológica linear. Dessa forma, em contraste com todo o aparato legal e tributário que foi elaborado para criar mecanismos de organização e subvenção do programa habitacional, problemas de ordem tributária continuam a constituir obstáculos para a alavancagem do desempenho da cadeia produtiva da construção industrializada. Barbosa (2011) cita, por exemplo, dois "anacronismos tributários": as elevadas alíquotas de ICMS sobre os itens industrializados, que acabam por incentivar o uso de processos tradicionais com componentes produzidos no próprio canteiro - e o cálculo das contribuições previdenciárias, que é efetuado a partir de um método simplificado, tendo como base a produtividade estabelecida pela NBR 12721 (ABNT, 2006). Os recolhimentos efetuados pelas empresas são comparados com os valores obtidos através desse procedimento, sendo necessária a complementação quando não atingem o percentual mínimo estipulado. A produtividade padrão é pautada em métodos tradicionais, não incorporando os benefícios em economia de mão de obra trazidos pelos processos industriais e penalizando a adoção de tecnologias nesse sentido (BARBOSA, 2011; BRESSIANI; HEINECK, 2004).

A isso se somam os problemas estruturais do país, tais como a elevada carga tributária e os encargos trabalhistas excessivos, o que leva a uma reflexão sobre a necessidade de que as políticas públicas não se limitem ao provimento da habitação, mas que incluam um esforço orquestrado para garantir a viabilização de sua construção com qualidade. Para tanto, é necessário, então, que haja uma compreensão aprofundada dos possíveis mecanismos de seleção tecnológica, resultando em um aprendizado que possa estabelecer as bases para o desenvolvimento de espécies tecnológicas mais adequadas.

\section{Sistemas tecnológicos inovadores}

As espécies tecnológicas que têm sido propostas ao mercado da construção brasileiro correspondem a sistemas que já existem e são largamente empregados em outras partes do mundo, permitindo ora a racionalização dos processos construtivos, ora a flexibilidade de configuração do espaço, ora, ainda, a individualização de soluções, entre outros. Trata-se, ainda assim, de inovação, dentro da perspectiva proposta por Dosi (2006), que coloca a introdução de sistemas já adotados em outros países ou em outros contextos como uma inovação tecnológica, quando inseridos em uma trajetória até então convencional.

A evolução de cada espécie tecnológica passa por diversos estágios. Metcalfe (1988) destaca a diferença entre a adoção e a difusão de um sistema. A adoção diz respeito à incorporação das inovações pelas empresas em suas atividades. Já a difusão diz respeito à importância econômica que determinada tecnologia vai assumindo ao longo do tempo. São estágios sequenciais no processo evolutivo dos sistemas tecnológicos, processo esse que pode ainda, em uma análise pormenorizada, ser subdividido em um maior número de etapas.

Assim, existem hoje sistemas ditos "inovadores" que começam a ser mais amplamente difundidos, mas foram inicialmente introduzidos em pequena escala, principalmente na década de 1990. Ainda sem o suporte de metodologias sistematizadas de avaliação das inovações, sua adoção dependia, em alguns casos, da disponibilidade financeira das construtoras para investimentos não só no desenvolvimento, mas também na constatação da viabilidade técnica e econômica (CÂMARA..., 2013).

Os sistemas de paredes de concreto armado moldadas no local, por exemplo, que até 2012 eram classificados pelo Sistema Nacional de Avaliação Técnica de Produtos Inovadores (Sinat) como inovadores, foram introduzidos no país há cerca de 30 anos (ORSINI, 2012). Os sistemas com perfis estruturais de aço formados a frio (Light Steel Framing ou LSF), por sua vez, ainda hoje considerados inovadores, foram introduzidos no país por volta de 1998 (HERNANDES, 2004), focando, na época, o setor da construção residencial de médio e alto padrão.

Alguns sistemas não conseguem passar dessa etapa inicial de sua evolução, como é o caso de fachadas pré-fabricadas para edifícios residenciais ou dos banheiros prontos, que praticamente se inviabilizaram no mercado habitacional (CÂMARA..., 2013). 
Dando continuidade ao processo evolutivo, identifica-se uma segunda etapa, que pode consistir na difusão do sistema dentro do mesmo nicho em que foi introduzido ou em sua adoção em um nicho diferente. Atualmente, no Brasil, as condições criadas pelas políticas públicas habitacionais têm tornado atrativo o nicho voltado para a produção de unidades habitacionais de baixa renda em escala. Nesse nicho, a etapa evolutiva seguinte depende do interesse que a inovação venha a despertar nas empresas do setor, as quais devem, então, conseguir uma validação para o sistema por meio de avaliação dele no Sinat. Dessa forma, o termo "sistema construtivo inovador" tem sido aplicado no Brasil com referência a sistemas que não possuem normalização prescritiva específica e que estão vinculados a esta avaliação, realizada pelo Sinat

O Sinat foi instituído pela Portaria n. 345, de 3 de agosto de 2007, no âmbito do PBQP-H, e entrou em operação em 2010, estabelecendo requisitos e critérios técnicos mínimos, que devem ser seguidos na elaboração de projetos utilizando as tecnologias inovadoras. O processo de análise inclui uma avaliação técnica e auditoria de qualidade no sistema, a partir da realização de ensaios de desempenho, que procuram prospectar o comportamento em uso para os materiais, componentes e sistemas construtivos.

Esse processo é realizado por instituições credenciadas - Instituição Técnica Autorizada (ITA) - e aborda aspectos como desempenho estrutural, segurança contra incêndio, estanqueidade, segurança no uso e operação, desempenho térmico, acústico e de luminosidade, entre outros. O Sinat define, inicialmente, as diretrizes de referência para avaliação dos sistemas e, caso estas não existam, a ITA elabora uma minuta de diretriz, que submete à apreciação do Sinat (ZANONI; SÁNCHEZ, 2013a).

No caso de aprovação do sistema, a ITA emite um Documento de Avaliação Técnica ou DATec. As avaliações técnicas fornecidas pelos DATecs são formatadas para comunicar a conformidade do produto ao uso pretendido, embora não tenham força de norma ou regulamentação (AMANCIO et al., 2012). Adicionalmente, trazem aos construtores e consumidores uma segurança com relação a um sistema ainda desconhecido em termos de desempenho (CAMPOS, 2010), constituindo uma garantia contra a ocorrência de problemas tais como os observados nas já mencionadas experiências de industrialização da construção dos anos 1980.

O processo de avaliação dos sistemas inovadores ainda é, entretanto, bastante incipiente: quase seis anos após sua regulamentação, o Sinat emitiu apenas um total de nove diretrizes e dezesseis DATecs. Sete destes DATecs estão vinculados à Diretriz Sinat n. 001 rev.2, referente a sistemas com paredes de concreto armado moldadas no local; seis DATecs estão vinculados à Diretriz Sinat n. 002: quatro deles dizem respeito a painéis estruturais; e dois dizem respeito a painéis de vedação, todos pré-fabricados; por fim, três DATecs estão vinculados à Diretriz Sinat n. 003 ver.1, referente a perfis estruturais de aço formados a frio (LSF) (BRASIL..., 2013).

A emissão de diretrizes e a emissão de DATecs para um sistema representam estágios evolutivos já bastante avançados no sentido de sua difusão. Entretanto, essa etapa representa não só uma garantia de desempenho e "[...] a consolidação de uma cultura de avaliação técnica, controle laboratorial e monitoramento da produção [...]" (ZANONI, SACHEZ, 2013a), mas também um desafio a ser transposto na competição das espécies inovadoras, já que demanda gastos consideráveis por parte do proponente do sistema e constitui condição expressa para a obtenção de financiamentos junto a determinadas instituições financeiras.

Sistemas construtivos inovadores tais como o Light Wood Framing, sistemas utilizando blocos de vedação em gesso e painéis de PVC já são adotados em alguns contextos, já possuem Diretrizes Sinat, mas não tiveram ainda nenhum DATec emitido. Já os sistemas com perfis de aço moldados a frio (LSF) e os sistemas de painéis prémoldados off-site estão numa etapa mais avançada, pois já são detentores de DATecs.

Os sistemas com LSF vêm aos poucos transpondo as dificuldades encontradas quando de sua adoção inicial, tais como sua adaptação para as condições de clima locais e o fornecimento mais organizado dos insumos, que, embora sejam ainda de difícil obtenção quando comparados aos insumos dos sistemas convencionais (CAMPOS, 2010), tendem a ter sua disponibilização facilitada, a partir do envolvimento de detentores de DATec do porte da multinacional Saint Gobain, fabricante de gesso acartonado. O sistema é empregado pontualmente em projetos habitacionais, e suas melhores chances de alcançar a escala desejável para sistemas com esse grau de industrialização estão em sua difusão no nicho que atende ao MCMV.

Os diversos sistemas de painéis pré-moldados, utilizando métodos e técnicas variados, por sua vez, representam uma possibilidade de inovação tecnológica efetiva. Objeto de vários estudos no Brasil e no exterior, esses sistemas têm grande potencial de evoluir sob vários aspectos, incluindo 
a melhoria de detalhes, como "[...] o assentamento de blocos com argamassas de alta aderência, simplificação dos sistemas de nervura e enrijecimento com concreto armado e uso de protensão [...]" (ZANONI; SACHEZ, 2013b).

Adiante, prosseguindo o processo evolutivo dos sistemas tecnológicos inovadores, existe um estágio mais avançado, que é atingido quando há uma articulação política suficiente para mobilizar as instituições em torno da sistematização dos parâmetros técnicos (ORSINI, 2012): trata-se do estágio que tem início quando uma norma específica para o sistema é elaborada, ampliando suas perspectivas de difusão. As possibilidades que se abrem para as empresas, quando o sistema prescinde dos dispendiosos e demorados DATecs, amplia significativamente o mercado, antes extremamente restrito.

Os sistemas em paredes de concreto moldadas no local, com sete DATecs emitidos, encontram-se neste estágio, consolidados a partir da aprovação da NBR 16055 (ABNT, 2012) (Parede de concreto moldada "in loco" para a construção de edificações - Requisitos e Procedimentos): estes sistemas passaram, desde então, a ser considerados convencionais, o que rompe diversas barreiras para sua difusão e diversifica as "unidades de seleção" que vão definir sua adequação ao meio daí em diante.

Nem todos os sistemas inovadores deverão percorrer essa trajetória, uma vez que nem todos visam ao nicho das unidades habitacionais em escala, ou aspiram a um financiamento que exija a chancela do Sinat. Entretanto, dentro das condições atuais do meio, os sistemas que passaram por esse processo evolutivo têm grandes chances de sobrevivência e difusão, não somente no nicho específico da habitação social em escala, mas também em diversos outros.

A entrada em vigor da Norma de Desempenho (ABNT, 2013) fortalece essa tendência, uma vez que todos os sistemas tecnológicos, e não somente os inovadores, deverão obedecer aos critérios de desempenho por ela definidos. Existe uma previsão de aumento de custo final da obra da ordem de $5 \%$ a $7 \%$ para as empresas que não cumprem requisitos mínimos de qualidade, principalmente as que atuam na construção econômica, o que deverá influir na competitividade dos sistemas utilizados (LIMA; OLIVEIRA, 2011).

Esse processo evolutivo demonstra que a adaptabilidade de um sistema para utilização com qualidade na construção em escala constitui, em si, uma importante "unidade de seleção".
Dessa forma, as "unidades de seleção" adotadas na análise da evolução de uma espécie tecnológica são, em geral, questões transversais, interdisciplinares, que perpassam discussões econômicas, sociais e culturais, entre outras. Perspectivas que podem constituir um filtro para a definição do sucesso de espécies tecnológicas incluem, por exemplo, seu grau de compatibilidade com a estrutura do setor, questão com um forte viés econômico, mas que destaca o caráter histórica e socialmente construído das "regras do jogo" (NORTH, 1990); ou a compatibilidade da imagem do sistema com as expectativas do usuário, questão de cunho mais marcadamente cultural, que sofre, porém, grande influência do desempenho tecnológico; ou, ainda, a compatibilidade do sistema com as necessidades e aspirações do usuário, dentro de uma perspectiva social. São abordagens complexas, das quais alguns aspectos serão discutidos a seguir.

\section{Unidades de seleção: a compatibilidade do sistema com a estrutura do setor}

A construção civil no Brasil tem sido caracterizada por seu foco em sistemas convencionais: até o início da expansão da construção habitacional em 2005, verificava-se a predominância absoluta do concreto moldado in loco e da alvenaria de tijolos. Ainda, a produção estruturava-se por meio de uma organização temporária, com grande diversidade de insumos e de fornecedores, além de fazer uso intensivo de mão de obra (FAZINGA; SAFFARO, 2012). A produtividade, nesse caso, está vinculada à intensidade do trabalho, o que faz com que a prioridade das construtoras seja a questão organizacional, levando-as a investir principalmente em novas formas de gerência e controles, inclusive de qualidade.

Assim, uma das particularidades do setor foi, ao longo de muitos anos, o esforço focado na inovação de gestão, em detrimento da inovação de sistemas construtivos (AMORIM, 1996). A partir de 2005, esse esforço intensificou-se, incluindo também as questões de logística (TAMAKI, 2013). Entretanto, nos últimos anos, houve uma absorção de inovações em materiais e sistemas construtivos por parte das empresas que chegou a suplantar a quantidade de inovações em projeto e em gestão, conforme levantamentos com as empresas construtoras de cinco estados e quatro diferentes regiões, realizado pelo Programa de Inovação Tecnológica (PIT) em seu diagnóstico setorial (CÂMARA..., 2013). 
Uma análise dessas inovações constatadas pelo PIT demonstra que elas foram principalmente de cunho incremental, o que parece estar ligado às características de um contexto que, em certos aspectos, inibe a inovação: a própria composição do setor de construção civil no Brasil constitui um fator limitante. Nele predomina a informalidade, que, embora decrescente, ainda correspondia a cerca de $62,6 \%$ da mão de obra empregada no setor em 2009 (contra 71,3\% em 2003) (NERI, 2011).

Entre as empresas formais, existe um grande número de pequenas empresas que não têm porte e estrutura suficientes para dedicar-se com eficácia à inovação; em contraste, algumas grandes empresas - $16 \%$ em número -, que empregam $60 \%$ da mão de obra, produzem $63 \%$ de todas as obras, possuem capital aberto na bolsa, sendo hoje controladas por empresas estrangeiras (GODEIRO;MONTEIRO; MARQUES, 2010).

Foi o crescimento da atuação dessas grandes empresas no mercado da construção habitacional que criou um contexto favorável para a industrialização, uma vez que a estrutura verticalizada delas viabiliza financeira e organizacionalmente a articulação necessária para os investimentos em maquinário e instalações e a concatenação das mudanças em vários níveis da cadeia produtiva. O caráter dessa coordenação pode ser esclarecido por meio de uma visão institucionalista do setor.

O termo "instituição" tem sentido amplo, que difere conforme o recorte analítico que se faz. As instituições estão relacionadas com as estruturas subjacentes que produzem uma regularidade de comportamentos em uma sociedade e coordenam as interações entre os agentes. Em uma abordagem ampla, elas seriam as "regras do jogo", que aumentam a previsibilidade das ações, destacandose seu caráter histórica e socialmente construído (NORTH, 1990). As variações institucionais que caracterizam o sistema econômico e afetam sua operação têm sido investigadas com maior detalhe pelas teorias institucionalistas, não só através de abordagens sociológicas, como também através de enfoques econômicos, tais como os mecanismos explicitados pela análise dos Custos de Transação de Williamson (1985).

Esses custos de transação seriam aqueles necessários para manter em funcionamento o sistema econômico. De acordo com Williamson (1985), determinados tipos de organização conseguem baixar os custos de transação de determinados tipos de atividades e tornar as empresas que as adotam mais competitivas.
A verticalização das empresas, que se observa atualmente no setor da construção habitacional no Brasil, permite que elas tenham flexibilidade e autonomia de tomar as decisões sobre o investimento, o emprego, a produção e a distribuição em todos os estágios do negócio que possuírem. A forma organizacional associada à integração vertical é a hierarquia. Esses arranjos verticais hierarquizados constituem, então, a organização mais adequada quando a transação exige ativos específicos - maquinário e instalações -, além de competências específicas para executar determinadas obras complexas (WILLIAMSON, 1985), e sua existência favorece, portanto, as possibilidades de desenvolvimento de sistemas mais industrializados.

Assim, os sistemas inovadores com paredes e os painéis de concreto, por exemplo, que podem ser classificados na categoria de vedações externas pesadas (densidade superficial $>100 \mathrm{~kg} / \mathrm{m}^{2}$ ) (ZANONI; SACHEZ, 2012b), demandam ativos específicos para o transporte e manuseio de painéis e formas (instalações e equipamento tais como ponte rolante e grua ou caminhão com guindaste de braço mecânico), além de recursos financeiros consideráveis.

Por sua vez, os sistemas que utilizam as paredes moldadas no local caracterizam-se por ciclos diários de montagem e desmontagem das fôrmas, que podem ser metálicas, de madeira ou de plástico, devendo ter um sistema validado pelo projetista e ser cuidadosamente monitorados na produção (ZANONI; SACHEZ, 2013b). Esses sistemas também demandam importantes ativos específicos, tais como gruas e o próprio sistema de fôrmas, que, embora sejam amortizados com o uso, representam um investimento inicial significativo.

Já para os sistemas de LSF, existe facilidade de obtenção dos perfis formados a frio perfilados, uma vez que são largamente utilizados pela indústria (SANTIAGO, 2008); os sistemas de vedação também são industrializados. O maquinário necessário para fabricação pode ser de pequeno porte, e a montagem não demanda necessariamente equipamentos de elevação. A verticalização é demandada, nesse caso, mais no nível dos fornecedores de componentes e materiais, o que é bem demonstrado pelo DATec n. 014, obtido pelo Grupo Saint-Gobain, cuja solução incorpora produtos de diversas de suas marcas: Brasilit, Isover, Placo e Weber.

A existência dos fornecedores para os materiais e componentes de novos sistemas é considerada como um dos fatores-chave para a definição de um paradigma tecnológico: a disponibilidade de um estoque ilimitado por um longo período favorece a 
continuidade, enquanto a certeza de um grande aumento em seu fornecimento no longo prazo viabiliza os investimentos e favorece a mudança (FREEMAN; PEREZ, 1988). A presença das "espécies" tecnológicas inovadoras e de seus fornecedores, assim como a presença de empresas construtoras verticalizadas no mercado brasileiro, são, portanto, fatores que geram um potencial de reorganização interna do sistema tecnológico como um todo, mas, por si só, não definem que as espécies inovadoras sejam as mais adequadas ao meio: independentemente de qual seja o nível de oportunidade, a adequação será constatada a partir da "apropriabilidade privada", ou seja, da medida na qual as empresas adotarem determinada solução, o que define o grau de compromisso dessas em relação às atividades de inovação (DOSI, 2006).

As empresas que adotam rapidamente os novos paradigmas tecnológicos não são, em geral, aquelas mais bem estabelecidas, uma vez que possuem conhecimento, infraestrutura e investimentos que poderão tornar-se obsoletos dentro de um novo sistema (FREEMAN; PEREZ, 1988). As grandes empresas brasileiras, durante muito tempo, organizaram-se em torno da construção convencional, e com a adoção de processos industriais elas deverão assistir à obsolescência de sua estrutura produtiva anterior, o que pode levá-las a atrasar o processo de industrialização.

Também existem questões de caráter cultural nas empresas, as quais podem contribuir para o atraso: entre os atributos que determinam a performance no que diz respeito à inovação, Coriat e Dosi (2002) identificam as especificidades de cada empresa em termos de processos organizacionais, posicionamentos e trajetórias. Existem, portanto, no próprio nível da organização das empresas, barreiras para a adoção de um direcionamento inovador, que muitas vezes estão mais relacionadas com os atributos internos do que com o contexto de provisão habitacional (TILLMANN, 2008), dizendo respeito não somente à infraestrutura produtiva, mas principalmente a questões de capital humano.

Assim, decisões de investimento referentes ao sucateamento de bens de capital envolverão sempre o cálculo visando a uma maximização de receitas (DOSI, 2006), mas também dependerão da cultura gerencial: as empresas oscilam entre a capacidade de adaptação ao meio existente e a capacidade de evolução que lhes permite adaptarse ao meio mutável.

Existem, portanto, situações estratégicas dinâmicas, que podem ser lineares ou não. Em alguns momentos, as empresas inserem-se dentro de dinâmicas lineares; em outros momentos - e principalmente em face de mudanças no meio -, os resultados não estão linearmente relacionados com a causa ou com a organização do input (BURGELMAN; GROVE, 2006).

No Brasil, as empresas que atuam no nicho da construção habitacional em escala parecem estar prontas para uma mudança de paradigma tecnológico, mas o processo evolutivo dos sistemas inovadores ainda está em curso.

\section{Unidades de seleção: a compatibilidade da imagem do sistema tecnológico com o sistema de expectativas do usuário}

No que diz respeito à habitação, a família padrão, que é atendida em suas aspirações pela conformação e imagem tradicional dela, em geral se mostra resistente à mudança. Essa resistência está relacionada ao fato de que o espaço residencial, enquanto cenário para a vida cotidiana, é fortemente ligado à rotina e aos costumes, que, segundo Weber (1995), são uma "educação interior da alma" e impõem um apego às regularidades, o que resulta em inibições dirigidas contra as inovações. A residência, enquanto cenário de atividade da família, constitui uma das áreas institucionais às quais pertencem os valores básicos das sociedades, em que o ritmo das mudanças sociais é mais lento (VILA NOVA, 2004). Ela oferece, portanto, maior resistência à mudança social, o que faz com que a imagem da tecnologia inovadora apareça como uma importante "unidade de seleção" das espécies tecnológicas a serem utilizadas em sua construção.

Sistemas que se assemelham aos sistemas convencionais, que usam os mesmos materiais e têm a mesma aparência final são, portanto, mais bem aceitos culturalmente. É o caso das paredes de concreto moldadas in loco ou ex-site. Por outro lado, alguns sistemas carregam uma imagem que pode ser uma barreira para sua difusão. Eles necessitam de um longo ciclo de maturação, pois, além de não corresponder à imagem a que os usuários estão habituados, rompem com práticas muito tradicionais no campo de sua aplicação.

Um exemplo são os sistemas em Light Steel Framing (LSF). Eles são baseados em perfis de aço galvanizado formados a frio, montados individualmente até formar um conjunto que dá forma ao edifício e o suporta. Esses perfis compõem uma estrutura leve, que é posteriormente 
vedada por painéis de aproximadamente $10 \mathrm{~mm}$ de espessura. Eles transmitem uma ideia de fragilidade, que entra em conflito com a cultura construtiva brasileira, baseada, esta, em materiais maciços e com pouca exigência de atenção à manutenção (SANTIAGO, 2008; CAMPOS, 2010). Os sistemas com vedação em placa de OSB e siding vinílico, em especial, enfrentam uma grande rejeição por parte dos usuários, pois "[...] reforçam o aspecto de casa americana [...]" (CRASTO, 2005, p. 216). A tentativa de esconder o material de vedação com argamassa acaba resultando em um sistema com baixo desempenho e propenso a patologias, uma vez que a aderência entre os dois materiais é inadequada. Os sistemas com placas cimentícias, por sua vez, embora possam transmitir uma ideia maior de solidez, muitas vezes são comprometidos pela qualidade das placas, que não são padronizadas ou apresentam alto índice de deformações higrotérmicas (CRASTO, 2005). As experiências de aplicação malsucedidas geram uma resistência ainda maior nas etapas subsequentes de evolução do sistema.

A questão da imagem pode ser resgatada, entretanto, a partir de uma utilização criteriosa: no caso do LSF, é de fundamental importância a elaboração de um estudo detalhado dos aspectos construtivos para garantir sua viabilidade técnica, a aceitação por parte dos usuários e a minimização de patologias (SANTIAGO, 2008). Uma pesquisa realizada junto aos moradores de um empreendimento construído de acordo com preceitos rígidos de qualidade em Cotias, na grande São Paulo, reforça essa hipótese, uma vez que foi constatado que os usuários caracterizaram sua moradia como "firme e sólida" (CAMPOS, 2010). Uma aceitação gradativa do sistema poderá ocorrer, então, a partir das experiências bemsucedidas e da divulgação da tecnologia não só entre os usuários, mas também entre os profissionais envolvidos (CAMPOS, 2010). Desde que as construções sejam bem executadas e apresentem um bom desempenho, a tendência é a de que a imagem negativa se dissipe - embora este processo deva ser lento. Além disso, os bons resultados com relação a prazos, custos e efetiva racionalização construtiva no momento da adoção inicial do sistema são estímulos importantes para a continuidade e sucesso de sua implantação e difusão (SALGADO, $1996^{1}$ apud REZENDE; BARROS; ABIKO, 2002).

\section{Unidades de seleção: a compatibilidade do sistema com as necessidades do usuário}

O cenário social do século XXI é extremamente dinâmico. A emergência de temas como a sustentabilidade, a necessidade de redução energética e material e a preservação do equilíbrio ambiental tem transformado as relações entre homem e meio ambiente. A introdução no contexto residencial dos novos aparelhos eletrônicos computadores, televisores, home theaters, entre outros - deu origem a novas possibilidades de interpretação do espaço e à sobreposição de atividades, incluindo a inserção de ambientes de trabalho, entretenimento, educação e outros; a introdução de novos hábitos - tais como os derivados da crise da família mononuclear, do desenvolvimento profissional das mulheres, do desaparecimento gradativo de serviçais domésticos, do aumento da longevidade e do envelhecimento da população - transformou as relações entre os setores social, de serviço e íntimo e deslocou as fronteiras do privado, da intimidade; a disponibilidade dos serviços de alimentação (entregas, congelados, etc.) mudou os parâmetros de estocagem, de preparação de consumo dos alimentos (BRANDÃO, 2003; BELLANGER, 2000; BERNARD, 2005; VILLA; ORNSTEIN, 2010).

Para acompanhar o intenso ritmo de inovação social e atender a uma variedade significativa de grupos domésticos (VILLA; ORNSTEIN, 2010), as unidades habitacionais deverão cada vez mais ser não somente adaptáveis, mas também flexíveis, dentro de um contexto em que a mudança é um fator permanente. Essa flexibilidade ou adaptabilidade do espaço, que pode ser proporcionada por determinados sistemas tecnológicos, tem a probabilidade de ser, então, uma importante unidade de seleção dos sistemas inovadores.

Schneider e Till $\left(2007^{2}\right.$ apud BARROS; PINA, 2012) argumentam a favor da habitação mais flexível: socialmente, o conceito de flexibilidade "habilita o morador a assumir o controle de sua habitação", permitindo que ele faça escolhas a respeito do espaço ao longo do ciclo de vida da moradia. Demograficamente, ele:

\footnotetext{
${ }^{2}$ SCHNEIDER, T.; TILL, J. Flexible Housing. Oxford:

Architectural Press, 2007.
}

\footnotetext{
${ }^{1}$ SALGADO, M. S. 210 f. Rio de Janeiro, 1996. Metodologia Para Seleção de Sistemas Construtivos Destinados a Produção de Habitações Populares. Tese (Doutorado em Engenharia de Produção) - Coppe, Universidade Federal do Rio de Janeiro, Rio de Janeiro, 1996.
} 
Permite ajustar os projetos aos modos de vida e às novas configurações familiares. Tecnicamente, pode permitir a incorporação de novas tecnologias $e$ a modernização das antigas [...]. (apud BARROS; PINA, 2012, p. 10).

Entretanto, uma grande parte dos sistemas submetidos à análise do Sinat apresenta restrições no que diz respeito à flexibilidade: "As paredes de concreto moldadas no local ou aquelas formadas por painéis não podem ser alteradas, removidas total ou parcialmente demolidas pelo usuário, visto que se caracterizam como elementos estruturais" (ZANONI; SANCHEZ, 2013a). O posicionamento de vãos e instalações deve ser determinado antes da construção e, por outro lado, deve haver uma compatibilização desde o projeto entre as características do sistema - comprimento máximo dos painéis, pé-direito e adequação das instalações, entre outras -, o que limita as possibilidades de intervenção posterior. As interfaces entre materiais e entre componentes - ligações, juntas constituem pontos sensíveis, que podem prejudicar a estabilidade estrutural ou a estanqueidade do sistema, se alterados.

Considerando o estágio evolutivo avançado em que esses novos sistemas encontram-se, verifica-se que a flexibilidade arquitetônica, embora pareça ser uma aspiração da sociedade contemporânea, ainda não é uma unidade de seleção importante, pelo menos para o nicho da construção habitacional em escala.

Uma hipótese que pode explicar tal fenômeno seria a da existência de uma ordem de prioridades, tal como a estabelecida para as necessidades humanas por Maslow e Stephens (2000), por meio da pirâmide de necessidades que propõe: na base da pirâmide, estariam questões mais ligadas à sobrevivência, tais como a necessidade de alimentação, sono e repouso, de abrigo, etc. Em seguida estariam as necessidades de segurança e as necessidades sociais (associação, participação, amizade, afeto e amor). No topo da pirâmide, como aspiração apenas dos grupos que já tivessem satisfeito as necessidades dos níveis anteriores, estariam as necessidades de estima (autoapreciação, autoconfiança, status e outras) e as de necessidades de autorrealização. $O$ fato de que habitações em escala têm como consumidoras prioritárias as classes $\mathrm{C}$ e $\mathrm{D}$ pode explicar a pouca importância que a questão da flexibilidade parece assumir na evolução das espécies tecnológicas submetidas à avaliação do Sinat: seja por influência direta da demanda, mas mais provavelmente por uma decisão dos construtores, a preocupação está em atender às necessidades ligadas à sobrevivência, uma vez que a flexibilidade e a necessidade de "assumir controle da habitação" (BARROS; PINA, 2012) estariam mais ligadas às questões de autoestima $\mathrm{e}$ autorrealização, situadas no topo da pirâmide.

Dentro dessa lógica, constata-se que os sistemas que possibilitam a personalização de soluções e a flexibilidade de configurações são mais utilizados em construções voltadas para classes mais altas. Esses sistemas podem ser mistos, quando conjugam paredes estruturais rígidas e paredes de vedação mais facilmente modificáveis - ou ainda do tipo planta livre, com vedações em sistemas em dry wall ou similar, facilmente reconfiguráveis.

Entretanto, outra hipótese para explicar a pouca relevância da flexibilidade como "unidade de seleção" está relacionada com a inserção da habitação no modo de produção capitalista (VILLA; ORNSTEIN, 2010), fazendo com que a moradia seja passível de análise como produto, objeto do mercado imobiliário. Existe, assim, uma demanda por um produto padrão, observada inclusive em uma parcela considerável de compradores, que procura atributos contabilizáveis no mercado imobiliário, para a determinação do valor de sua residência. A flexibilidade não parece ser um desses atributos.

\section{Conclusão: considerações sobre perturbações possíveis}

Embora tecnologias construtivas industrializadas já tenham sido desenvolvidas e gradativamente disponibilizadas no mercado brasileiro há algumas décadas, a difusão dessas novas "espécies" tecnológicas tem sido lenta.

Nos últimos cinco a dez anos, no Brasil, tem-se constatado um processo de aceleração no sentido de evolução de certos sistemas inovadores que começa a ter importância econômica dentro do setor da construção habitacional no país. Porém, qualquer mudança de paradigma vai exigir ajustes em todo o sistema socioeconômico e a transposição de muitos obstáculos.

As políticas de inovação do país ainda estão sendo articuladas, e seu reflexo no setor da construção civil é bem menor do que se observa em outros campos. As políticas econômicas, sociais e, sobretudo, habitacionais, por sua vez, parecem ter uma maior importância sobre o ambiente evolutivo das tecnologias de construção, mas geram tendências contraditórias.

Dentro desse contexto, um nicho importante de desenvolvimento de sistemas ditos "inovadores" é a construção habitacional em escala para baixa renda. Esses sistemas devem ser submetidos à 
aprovação do Sinat enquanto não possuem normas específicas. Algumas tendências - tais como os sistemas de paredes de concreto moldados in loco, os diversos sistemas de painéis moldados e os sistemas de perfis leves moldados a frio - têm-se consolidado, a partir do mecanismo de seleção que a obtenção da chancela do Sinat representa - não só do ponto de vista tecnológico, como do ponto de vista financeiro.

Por outro lado, em nichos diferentes, surgem também produtos imobiliários com concepção inovadora, em sintonia com o intenso ritmo de inovação social, possibilitando a flexibilização total do espaço, a busca da sustentabilidade e outros (CÂMARA..., 2013), o que viabiliza a introdução e a difusão de sistemas que ainda não são viáveis para a construção habitacional de larga escala.

As diversas "unidades de seleção" que atuam ao longo da evolução das espécies tecnológicas têm caráter transversal e determinam o nível de sucesso dos sistemas. Cada recorte transversal reflete uma perspectiva única, e as tentativas de identificação das "unidades de seleção" partem do conhecimento do meio e das forças nele atuantes, em determinado momento.

A existência dessa infinidade de possíveis "unidades de seleção" demonstra que as contingências específicas das quais o sucesso depende são muito dificilmente acessadas a priori (BURGELMAN; GROVE, 2006). Apesar dessa dificuldade, as tentativas de compreensão do processo evolutivo, dentro de cada contexto e para cada "espécie" tecnológica, permitem não somente avaliar os efeitos das inovações no meio, mas também influenciar a sobrevivência de "espécies" tecnológicas que privilegiem a prospecção de um espaço coerente e de um mundo sustentável, por meio da implementação de programas e políticas públicas.

Não é evidente que a seleção natural produza-se no sentido de favorecer demandas de qualidade tecnológica e social. Torna-se imprescindível, então, a elaboração de políticas públicas e uma mobilização de arquitetos, engenheiros e gestores para a promoção de estratégias que possam contribuir para o surgimento de espécies em sintonia com as demandas sociais emergentes: o setor da construção necessita, dessa forma, de "políticas de jardinagem", destinadas a "proteger as espécies mais frágeis" e a fazê-las evoluir (AROCENA; SULTZ, 2005). Embora talvez elas não sejam as mais adaptadas em um meio dominado por imperativos econômicos, elas podem primar pelo desempenho quanto a questões tecnológicas e sociais.
Essa tentativa de interferir na evolução das espécies não tem resultado garantido: “[...] dentro de sistemas sociais organizados, as chances são relativamente grandes de que atividades sejam desenvolvidas como planejadas. Isto não significa necessariamente que os efeitos ocorram conforme pretendido [...]” (LUHMANN, $1981^{3}$ apud ARAÚJO; WAITZBORT, 1999, p. 192). Mas não se trata de traçar caminhos definidos para a construção habitacional brasileira: diante da complexidade do contexto, é necessário desenvolver uma compreensão realista, dentro da consciência da pluralidade de possíveis interpretações; qualquer estratégia deve partir mais da elaboração de sentidos e visões do que de programas específicos ou planejamentos rígidos a serem seguidos. As trajetórias devem sofrer adaptações na medida em que avançarem, de acordo com as reações que forem sendo observadas no sistema. Enfim, esse processo tem tanto mais chances de ser bem-sucedido, quanto mais incorporar perspectivas interdisciplinares e sistêmicas.

\section{Referências}

ALLEN, P. Evolution, iInovation and Economics. In: DOSI, G. et al. (Eds.) Technical Change and Economic Theory. London: Pinter, 1988. p. 95119.

AMANCIO, R. et al. Avaliações Técnicas de Produtos de Construção Inovadores no Brasil. In: JORNADAS ENGENHARIA PARA A SOCIEDADE, Lisboa, 2012. Anais... Lisboa, 2012.

AMORIN, S. L. Inovações Tecnológicas nas Edificações: papéis diferenciados para construtores e fornecedores. Gestão e Produção, v. 3, n. 3, p. 262-274, dez. 1996.

ARAUJO, C.; WAITZBORT, L. Sistema e Evolução na Teoria de Luhmann. Lua Nova, v. 47, p. 179-200, 1999.

AROCENA, R.; SUTZ, J. Conhecimento, Inovação e Aprendizado: sistemas e políticas no norte e no sul. In: LASTRES, H. M. M.; CASSIOLATO, J. E.; ARROIO, A. (Orgs.). Conhecimento, Sistemas de Inovação e Desenvolvimento. Rio de Janeiro: UFRJ; Contraponto, 2005.

ASSOCIAÇÃO BRASILEIRA DE NORMAS TÉCNICAS. NBR 15575: edifícios habitacionais: desempenho. Rio de Janeiro, 2013.

\footnotetext{
${ }^{3}$ LUHMANN, N. The Improbability of Communication. International Science Journal, v. 23, p.122-123, 1981.
} 
ASSOCIAÇÃO BRASILEIRA DE NORMAS TÉCNICAS. NBR 12721: avaliação de custos unitários e preparo de orçamento de construção para incorporação de edifício em condomínio. Rio de Janeiro, 2006.

ASSOCIAÇÃO BRASILEIRA DE NORMAS TÉCNICAS. NBR 16055: paredes de concreto moldadas no local para a construção de edificações. Rio de Janeiro, 2012.

BARBOSA, R. N. P. C. Entraves à Industrialização. Construção e Mercado, v. 123. p. 50-52, out. 2011.

BARROS; R. R. M. P.; PINA, S. A. M. G. Sinfonia Inacabada da Habitação Coletiva: lições a partir do PREVI para uma arquitetura de possibilidades. Ambiente Construído, Porto Alegre, v. 12, n. 3, p. 7-26, jul./set. 2012.

BELLANGER, F. Habitat(s): questions et hypothèses sur l'évolution de l'habitat. Paris: Éditions de 1' Aube, 2000.

BERNARD, Y. Contribuição da Psicologia Ambiental Para a Política de Construção de Moradias. Psicologia USP, v. 16, n. 1/2, p. 213222, 2005.

BRASIL. Presidência da República. Lei no 11.124, de16 de junho de 2005, dispõe sobre o Sistema Nacional de Habitação de Interesse Social SNHIS, cria o Fundo Nacional de Habitação de Interesse social e Institui o Conselho Gestor do FNHIS. Diário Oficial da União, 17 de junho de 2005.

BRASIL. Presidência da República. Lei no 10.931 , de 02 de agosto de 2004, dispõe sobre o patrimônio de afetação de incorporações imobiliárias, Letra de Crédito Imobiliário, Cédula de Crédito Imobiliário, Cédula de Crédito Bancário, altera o Decreto-Lei n ${ }^{\circ} 911$, de $1^{\circ}$ de outubro de 1969, as Leis no 4.591 , de 16 de dezembro de 1964 , n⿳ -7.728 , de 14 de julho de 1965, e n⿳0 10.406 , de 10 de janeiro de 2002, e dá outras providências. Diário Oficial da União, 03 de agosto de 2004.

BRANDÃO, D. Q. A Personalização do Produto Habitacional e as Novas Tecnologias no Processo Construtivo. In: SIMPÓSIO BRASILEIRO DE GESTÃO E ECONOMIA DA CONSTRUÇÃO, 3., São Carlos, 2003. Anais... São Carlos: UFSCar, 2003.
BRASIL. Ministério das Cidades. Secretaria Nacional da Habitação Programa Brasileiro da Qualidade e Produtividade do Habitat (PBQP-H) Sistema Nacional de Avaliações Técnicas. [Apresentação power point 13 slides]. Disponível em:

<http://www.cbic.org.br/sites/default/files/Projeto $\% 202 \% 20-\% 20$ SiNAT-\%20CBIC.pdf $>$. Acesso em: 27 jul. 2013.

BRASIL. Ministério das Cidades. Secretaria Nacional de Habitação. Déficit Habitacional no Brasil 2008. Brasília, DF: Ministério das Cidades, 2011.

BRESSIANI, L.; HEINECK, L. F. M. Recolhimento de INSS em Obras de Construção Civil: um comparativo entre os consumos teóricos de mão-de-obra expressos na NBR 12721 e o consumo real em uma obra. In: ENCONTRO NACIONAÇ DE ENGENHARIA DE PRODUÇÃO, 24., Florianópolis, 2004. Anais... Florianópolis, 2004.

BURGELMAN, R.; GROVE, A. S. Nonlinear Strategic Dynamics in Intel's Evolution . In: ÉCOLE POLYTECHNIQUE SEMINAIRE, 1., Paris, 2006. Présentations... Paris: Ecole Polytechnique, 2006.

CÂMARA BRASILEIRA DE INDÚSTRIA DA CONSTRUÇÃO. Programa de Inovação Tecnológica. Disponível em: <http://www.pit.org.br/1a-fase/inovacao-nobrasil>. Acesso em: 17 jun. 2013.

CAMPOS, H. C. Avaliação Pós-Ocupação de Edificações Construídas no Sistema Light Steel Framing. 148 f. Ouro Preto, 2010. Dissertação (Mestrado em Engenharia Civil) - Escola de Minas, Universidade Federal de Ouro Preto, Ouro Preto, 2010.

CARDOSO, F. F. Desafios Tecnológicos Lançados pelo Programa Brasileiro da Qualidade e Produtividade na Construção Habitacional. In: ENCONTRO NACIONAL DE TECNOLOGIA DO AMBIENTE CONSTRUÍDO, 7. Florianópolis, 1998. Anais... Florianópolis: ANTAC, 1998. p. 267-275.

CÁRIO, S. A. F.; PEREIRA, F. C. B. Inovação e Desenvolvimento Capitalista: referências dinâmica. Revista de Ciências Humanas da Universidade do Extremo Sul Catarinense, Criciúma, v. 7, n. 1, p. 81-102, 2001.

CORIAT, B.; DOSI, G. Problem-Solving and Coordination-Governance: advances in a competence-based perspective on the theory of the firm. Revista Brasileira de Inovação, v. 1, n. 1, p. 49-84., jan./jun. 2002. 
CRASTO, R. C. M. Arquitetura e Tecnologia em Sistemas Construtivos Industrializados: light steel framing. $231 \mathrm{f}$. Ouro Preto, 2005. Dissertação (Mestrado em Engenharia Civil) - Escola de Minas, Universidade Federal de Ouro Preto, Ouro Preto, 2005.

DOSI, G.; NELSON, R. An Introduction to Evolutionary Theories in Economics. Journal of Evolutionary Economics, n. 4, n. 3, p. 153-172, 1994.

DOSI, G. Mudança Técnica e Transformação Industrial: a teoria e sua aplicação à indústria de semicondutores. Campinas: Unicamp, 2006.

DOSI, G.; ORSENIGO, L. Coordination and Transformation: an overview of structures, behaviours and change in evolutionary environments. In: DOSI, G. et al. (Eds.). Technical Change and Economy Ttheory. London: Pinter, 1988.

FAZINGA, W. R.; SAFFARO, F. A. Identificação dos Elementos do Trabalho Padronizado na Construção Civil. Ambiente Construído, Porto Alegre, v. 12, n. 3, p. 27-44, jul./set. 2012.

FREEMAN, C.; PEREZ, C. Structural Crisis and Edjustment, Business Cycles and Investment Behavior. In: In: DOSI, G. et al. (Eds.) Technical Change and Economic Theory. London: Pinter; 1988. p. 38-66.

GODEIRO, N.; MONTEIRO, C.; MARQUES, G. A Exploração do Trabalhador da Construção Civil no Brasil e Sua Expressão em Belém do Pará. Belém: ILAESE, 2010.

HERNANDES, H. Sistema Construtivo Steel Graming. Palestra CBCA, 2004. Disponível em: $<w w w . c b c a-$

iabr.org.br/upfiles/downloads/apresent/palestra_A BM2.doc>. Acesso em: 20 nov. 2012.

KIRCHNER, R. et al. Análise das Características de Trabalhadores da Construção Civil no Sul do Brasil: no período de 2002 a 2009. Trabalho \& Educação, Belo Horizonte, v.2 0, n. 1, p.47-58, jan./abr. 2011.

KUPFER, D. Uma Abordagem Neo-

Schumpeteriana da Competitividade Industrial. Ensaios FEE, Porto Alegre, v. 17, n. 1, p. 355372, 1996.

LIMA, D.; OLIVEIRA, K. Caem Tributos da Construção Para Minha Casa, Minha Vida. Exame, São Paulo, 01 dez. 2011. Disponível em: <http://exame.abril.com.br/economia/brasil/habitac ao/noticias/governo-reduz-tributos-da-construcaopara-minha-casa-minha-vida>. Acesso em: 12 out. 2013.
LIMA JÚNIOR., J. R. Alerta de Bolha. Carta do NRE Poli-USP, São Paulo, v. 25, jul./set. 2011.

LUHMANN, N.; TORRES NAFARRATE, J. Introdução à Teoria dos Sistemas: aulas publicadas por Javier Torres Nafarrate. Petrópolis, RJ: Vozes, 2009.

MARICATO, E. A Nova Política Nacional de Habitação. O Valor, 2005. Disponível em: <http://www.fau.usp.br/depprojeto/labhab/bibliote ca/textos/maricato_novapoliticahab.pdf $>$. Acesso em: 03 mar. 2012.

MARICATO, E. O Ministério das Cidades e a Política Nacional de Desenvolvimento Urbano. Políticas Sociais: Acompanhamento e Análise. v. n. 12, p. 211- 220, fev. 2006.

MASLOW, A; STEPHENS, D. (Eds.). The Maslow Business Reader. New York: Wiley, 2000.

METCALFE, J. S. The Diffusion of Innovation: an interpretative survey. In: DOSI, G. et al. (Eds.) Technical Change and Economic Theory. London and New York: Pinter, 1988. p. 560-589.

MOYSÉS, A.; BORGES, E. M. A Retomada dos Financiamentos Públicos Imobiliários e a Produção Para os Setores Populares: impactos na reconfiguração espacial da RM de Goiânia. In: ENCONTRO NACIONAL DA ANPUR ,14., Rio de Janeiro, 2011. Anais... Rio de Janeiro. 2011.

NERI, M. C. (Coord.). A Nova Classe Média. Rio de Janeiro: FGV/ IBRE, 2008.

NERI, M. C. (Coord.). Trabalho, Educação e Juventude na Construção Civil. Rio de Janeiro: FGV/CPS, 2011.

NORTH, D. C. Institutions, Tnstitutional Change and Economic Performance. Cambridge: Cambridge University Press, 1990.

ORSINI, R. Paredes Normatizadas. Techné, v. 20, n. 183 , p. 40-45, jun. 2012.

OSCAR, N. Um Mercado Sob Suspeita. Exame, v. 46, n. 3, p. 32-47, 22 fev. 2012.

REZENDE, M. A. P.; BARROS, M. M. S. B.; ABIKO, A. K. Barreiras e Facilitadores da Inovação Tecnológica na Produção de Habitações Populares. In: ENCONTRO NACIONAL DE TECNOLOGIA DO AMBIENTE CONSTRUIIDO ENTAC, 9., Foz do Iguaçu, 2002. Anais... Foz do Iguaçu: ANTAC, 2002. p. 895-904. 
SANTIAGO, A. K. O Uso do Sistema Light Steel Framing Associado a Outros Sistemas Construtivos Como Fechamento Vertical Externo Não-Estrutural. 153 f. Ouro Preto, 2008 Dissertação (Mestrado em Engenharia Civil) Escola de Minas, Universidade Federal de Ouro Preto, Ouro Preto, 2008.

SCHUMPETER, J. A. Teoria do

Desenvolvimento Econômico: uma investigação sobre lucros, capital, crédito, juro e o ciclo econômico. São Paulo: Nova Cultural, 1985.

SILVA J. C. B.; AMORIM, S. R. L. A

Contribuição dos Sistemas de Classificação Para a Tecnologia BIM: uma abordagem teórica. In:

ENCONTRO DE TECNOLOGIA DE

INFORMAÇÃO E COMUNICAÇÃO NA CONSTRUÇÃO, 5., Salvador, 2011. Anais... Salvador, 2001.

TAMAKI, L. Gafisa Implementa Sistema De Logística Industrial Em Obra-Piloto. Disponível em:

<http://www.piniweb.com.br/construcao/tecnologi a-materiais/artigo189522-2.asp>. Acesso em: 18 fev. 2013.

TILlMANN, P. A. Diretrizes Para a Adoção da Customização em Massa na Construção Habitacional Para Baixa Renda. 162 f. Porto Alegre, 2008. Dissertação (Mestrado em Engenharia Civil) - Programa de Pós-Graduação em Engenharia Civil, Univesidade Federal do Rio Grande do Sul, Porto Alegre, 2008.
VILLA, S. B.; ORNSTEIN, S. W. Projetar Apartamentos Com Vistas à Qualidade Arquitetônica a Partir dos Resultados da Avaliação Pós-Ocupação (APO) Gestão \& Tecnologia de Projetos, v. 5, n. 2, p. 35-60, 2010.

VILA NOVA, S. Introdução à Sociologia. São Paulo: Atlas, 2004.

WEBER. M. L'Organization et les Puissances de la Societé Dans Leur Rapport Avec l'Économie. Paris: Bussière, 1995. v. 2.

\section{WILLIAMSON, O. E. The Economic} Institutions of Capitalism: firms, markets, relational contracting. New York: The Free Press, 1985.

ZANONI, V. A. G.; SÁNCHEZ, J. M. M. Painéis Pré-Fabricados Com Blocos Cerâmicos Materials and Materials. 2013a. Disponível em:

$<$ http://materialsandmateriais.blogspot.com.br/201 3/03/artigo-tecnico-at-10-paineis-pre.html>. Acesso em: 20 abr. 2013.

\section{ZANONI, V. A. G.; SÁNCHEZ, J. M. M.} Inovação na Construção: considerações a partir das diretrizes e dos documentos de avaliação técnica do SINAT 2012. 2013b. Materials and Materials Disponível em:

<http://materialsandmateriais.blogspot.com.br/201 3_03_01_archive.html>. Acesso em: 20 abr. 2013.

ZIGMANTAS, L. G. M. Expectativas da Caixa Quanto à Implantação das Normas de Desempenho de Edifícios Até 5 Pavimentos. In: SEMINÁRIO HABITAÇÃO, São Paulo, 2005. Anais... São Paulo, 2005. p. 57-66.

Maria Luiza de Castro

Escola de Arquitetura | Universidade Federal de Minas Gerais | Rua Paraíba, 697, Funcionários | Belo Horizonte - MG - Brasil | CEP 30130-140 | Tel.: (31) 3409-8800 | E-mail: luizadecastro@ufmg.br

Paulo Gustavo von Kruger

Escola de Arquitetura | Universidade Federal de Minas Gerais | Tel.: (31) 3409-8800 Ramal 8851 | E-mail: vonkruger@vonkruger.arq.br

Revista Ambiente Construído

Associação Nacional de Tecnologia do Ambiente Construído

Av. Osvaldo Aranha, $99-3^{\circ}$ andar, Centro

Porto Alegre - RS - Brasil

CEP $90035-190$

Telefone: +55 (51) 3308-4084

Fax: +55 (51) 3308-4054

www.seer.ufrgs.br/ambienteconstruido

E-mail: ambienteconstruido@ufrgs.br 